\title{
CO-ESTIMATION OF SAXAGLIPTIN AND ENALAPRIL IN LIPOSPHERES: HPLC METHOD DEVELOPMENT, VALIDATION AND OPTIMIZATION USING RESPONSE SURFACE TECHNIQUE
}

\author{
SAFIRAH MAHEEN ${ }^{1,2}$, AKHTAR RASUL ${ }^{1 *}$, HAFEEZ U KHAN ${ }^{2}$, GHULAM ABBAS $^{1}$, \\ MALIK SAADULLAH ${ }^{1}$, SAMINA AFZAL ${ }^{3}$, MARIAM SHARIF ${ }^{2}$, KHURRAM AFZAL ${ }^{3}$, \\ FATIMA TARIQ ${ }^{2}$ and PERVAIZ A SHAH ${ }^{4}$
}

${ }^{1}$ Faculty of Pharmaceutical Sciences,

Government College University Faisalabad, Faisalabad, Pakistan

${ }^{2}$ College of Pharmacy, University of Sargodha, Sargodha, Pakistan

${ }^{3}$ Faculty of Pharmacy, Bahauddin Zakariya University, Multan, Pakistan

${ }^{4}$ University College of Pharmacy,

University of The Punjab, Lahore, Pakistan

\begin{abstract}
The co-existence of hypertension with diabetes demands combination therapy. Therefore, in this study, a simple, sensitive and precise HPLC method was developed to estimate Saxagliptin (SG) and Enalapril (EP) from sustained-release lipospheres choosing acetonitrile, methanol and buffer in a ratio of $40: 40: 20$ as mobile phase. Box-Behnken Design was used to study the impact of flow rate, detection wavelength and mobile phase $\mathrm{pH}$ on retention time and tailing factor of both drugs. A $10 \mu \mathrm{L}$ injection volume at a flow rate of $1 \mathrm{~mL} / \mathrm{min}$ under a column pressure of $1400 \mathrm{psig}$ with at a detection wavelength of $212 \mathrm{~nm}$ was run for $08 \mathrm{~min}$. The optimized retention time for EP and SG was observed as 2.12 and 4.07 min respectively whereas the tailing factor for EP and SG were found to be 1.26 and 1.56 respectively. The method was validated as per ICH guidelines where correlation coefficients $\left(\mathrm{R}^{2}\right)$ for SG and EP were found to be 0.9989 and 0.9995 respectively in linearity analysis and \% RSD for interday and intraday precision was observed $<2 \%$. The average $\%$ recovery of drugs was found to be $98.92 \%$ while lipospheres assay showed $98.91 \%$ EP and $99.89 \%$ SG contents. The LOD for $\mathrm{EP}$ and SG was found to be $0.006 \mu \mathrm{g} / \mathrm{mL}$ and $0.012 \mu \mathrm{g} / \mathrm{mL}$ and LOQ was observed as $0.22 \mu \mathrm{g} / \mathrm{mL}$ for EP and $0.25 \mu \mathrm{g} / \mathrm{mL}$ for SG respectively. The $\%$ RSD for system suitability was also $<1 \%$ for both drugs. The developed method proved itself rapid, cost-effective, and accurate in detecting SG and EP from the selected formulation.
\end{abstract}

Diabetes Mellitus is a group of metabolic disorders and characterized by the presence of elevated glucose levels (hyperglycemia) that can result from defects in insulin secretion, action, or both. The development of diabetes involves several pathogenic mechanisms ranging from autoimmune destruction of the $\beta$-cells of the pancreas with consequent insulin deficiency to abnormalities which ultimately result in insulin resistance. Chronic hyperglycemia in diabetes may further be a cause of long-term damage, dysfunction, and failure of different organs, including eyes, kidneys, nerves, heart, and blood vessels. The reasons for these concurrent abnormalities are emerging from a decrease in the metabolism of carbohydrate, fat, and protein which is because of actually deficient action or secretion of insulin on target tissues (1). Hypertension has also been reported as a very common comorbid condition in diabetes and is characterized as an elevated blood pressure ( $>140 / 90 \mathrm{mmHg}$ ) which may be due to the presence of a higher level of glucose in blood vessels. Hypertension affects $30-50 \%$ of diabetic patients and this effect depends on the level of obesity, ethnic background, and age factor. Hypertension in diabetic patients may significantly increase the risk of both macrovascular and microvascular complications, including stroke, coronary artery disease, peripheral vascular disease, retinopathy, nephropa-

\footnotetext{
* Corresponding author: e-mail: akhtar.rasul@gcuf.edu.pk
} 
thy, neuropathy, and possibly mortality (2). A necessary control of hypertension in diabetes can save patients from these multiple complications either microvascular or macrovascular. The target blood pressure in such patients should be less than 130/90 $\mathrm{mmHg}(3)$.

For effective hyperglycemic control, DPP4 (dipeptidyl peptidase 4) inhibitors such as saxagliptin (SG) are widely used which facilitate glucose-dependent insulin secretion. Saxagliptin reduces glucagon release, slows down gastric emptying, and reduces appetite by increasing the levels of active glucagon-like peptide-1 (4). The angiotensin-converting enzyme (ACE) inhibitors are usually considered as a preferred choice in managing hypertension in diabetic patients as they can effectively slow the progression of kidney failure and cardiovascular mortality (3, 5). Among these, Enalapril Maleate (EP) has the ability to reduce cardiovascular mortality and morbidity (6).

A review of literature has revealed that a few analytical methods like LC-Mass spectrometry, HPLC, and spectroscopic methods have been developed for the estimation of SG and EP either individually or in combination with other antidiabetic drugs like metformin but a method for the simultaneous estimation of SG and EP in a pharmaceutical dosage form has not been found (7-8). Most of these methods had a high retention time ranging from 7 to 12 min and a longer run time of approximately $10 \mathrm{~min}$ or greater, thereby resulting in higher cost and time consumption. The present work aimed at developing a simple, rapid, and accurate method for the quantification of Saxagliptin (SG) and Enalapril (EP) present in lipospheres. The HPLC analytical method was developed in the mobile phase, optimized by using a response surface technique (9) known as Box-Behnken design (BBD), and consequently validated in accordance with the ICH guidelines and recommendations by analyzing the developed method for accuracy, recovery, linearity, limit of detection, limit of quantification, intraday, interday precision freeze-thaw stability of drugs in the mobile phase, system suitability and assay of prepared lipospheres for EP and SG.

\section{EXPERIMENTAL}

\section{Materials}

Saxagliptin and Enalapril were generously gifted by Getz Pharma Pakistan (Pvt) Ltd Karachi and Mass Pharma Pakistan (Pvt) Ltd Lahore, Pakistan. The HPLC grade chemicals of high purity were used in this study. HPLC-grade acetonitrile was obtained from RCI Labscan Limited, methanol from Fischer Chemical, and potassium dihydrogen phosphate was supplied by Merck. All of the used chemicals and reagents were of analytical grade.

\section{Preparation of lipospheres}

The solvent evaporation approach was applied to prepare SG-EP loaded lipospheres formulation. Initially, a solution of Carnauba wax in $50 \mathrm{~mL}$ Chloroform was prepared followed by the addition of both drugs in this lipid solution. The lipid solution was added into an already prepared hot aqueous solution of T-20 maintained at $75^{\circ} \mathrm{C}$ with continuous homogenization under ambient conditions. The subsequent pre-emulsion was transferred into cold water $\left(1-4^{\circ} \mathrm{C}\right)$ and mixed with a magnetic stirrer. The obtained lipospheres were allowed to recrystallize at room temperature, filtered and dried. This approach was repeated by changing three factors to obtain all formulations including the selected optimized one by keeping the ratio of aqueous phase volume and drug concentration constant (10).

\section{Chromatographic conditions}

As depicted in Table 1, different volumetric ratios of methanol, acetonitrile, potassium dihydrogen phosphate, and distilled water were used to prepare five different mobile phases. In the first step, the $\mathrm{pH}$ was adjusted for each of these mobile phases and air bubbles were removed by using an ultrasonicator (D-78224, Shingen/Htw, Germany). Finally, the mobile phases were allowed to run through C18

Table 1. Composition of different mobile phases.

\begin{tabular}{|c|c|c|}
\hline Sr. NO & Mobile phase composition & Ratio (V:V) \\
\hline M1 & Distilled water $:$ methanol & $50: 50$ \\
\hline M2 & Acetonitrile : distilled water $:$ buffer $(\mathrm{pH} 3.5)$ & $40: 20: 40$ \\
\hline M3 & Methanol $:$ buffer $(\mathrm{pH} 3.5)$ & $50: 50$ \\
\hline M4 & Acetonitrile $:$ distilled water & $50: 50$ \\
\hline M5 & Acetonitrile $:$ methanol $:$ buffer $(\mathrm{pH}: 3)$ & $40: 40: 20$ \\
\hline
\end{tabular}


analytical columns (CLC-ODS, Shin-Pack, Shimadzu $)$ of assorted dimensions $(250 \mathrm{~mm} \times 4.6$ $\mathrm{mm}, 5 \mathrm{um}$ particle size). The entire HPLC system was maintained at ambient conditions and the mobile phase was filtered with a $0.22 \mu \mathrm{m}$ membrane filter before running through the system. Both drugs, EP and SG were detected at a wavelength of 212 $\mathrm{nm}$. The composition and $\mathrm{pH}$ of the mobile phase were optimized by comparing chromatograms developed for each of the mobile phases. Prior to injecting the sample solution, each mobile phase was allowed to run through the HPLC system for at least $30 \mathrm{~min}$ in order to equilibrate the system. The mobile phase M5 was finally selected because sharp peaks within short retention time were achieved for both drugs.

\section{Instrument}

High-Performance Liquid Chromatographic system consisting of Shimadzu LC-10AT and LC10AT VP series HPLC pumps with a $20 \mu \mathrm{L}$ sample loop that was operated manually and SPD 10A VP UV-Visible detector was used in this study. The output signals were integrated by Shimadzu CLASSVP Version 6.12 SP1 software. The second system used for system suitability studies was an Agilent HPLC system consisting of model series 1200 UV visible detector, series 1200 LC pump, series 1200 manual injector and a series 1200 column oven.

\section{Box-Behnken design}

After choosing a suitable mobile phase, the Box-Behnken design (BBD) was applied to optimize the experimental conditions of the HPLC method. In $\mathrm{BBD}$, detection wavelength, flow rate and $\mathrm{pH}$ of buffer were used at three factorial levels coded as $-1,0$ and +1 as three independent variables (Table 2) in order to optimize tailing factors $\left(\mathrm{Y}_{3}: \mathrm{EP}, \mathrm{Y}_{4}: \mathrm{SG}\right)$ and retention times $\left(\mathrm{Y}_{1}: \mathrm{EP}\right.$, $\left.\mathrm{Y}_{2}: \mathrm{SG}\right)$ of SG and EP that were used as a response or dependent variables. The software suggested 17 experimental runs for analysis and had explained the antagonistic, synergistic, individualized and interactive effect of variables on studied responses in the form of polynomial equations. ANOVA was applied in order to demonstrate the importance of studied independent factors.

\section{Preparation of standard solution}

Equal amounts of SG and EP were accurately weighed and a small amount of mobile phase was added to dissolve both drugs. To prepare a standard stock solution of $100 \mathrm{ng} / \mathrm{mL}$ of SG and EP, the initial solution was diluted with more mobile phase. Working solutions were further prepared by suitably diluting the stock solution with the mobile phase at different ranges of concentration. For complete dissolution, the solution was sonicated for $5 \mathrm{~min}$ and then equilibrated to room temperature (11).

\section{Validation of HPLC method Linearity}

Linearity indicates a method's capability to obtain test results which are directly proportional to the concentration of the sample over a given range (12). To determine linearity, drug solutions at the concentration range of $2-12 \mathrm{ng} / \mathrm{mL}$ were prepared and the correlation coefficient $\left(\mathrm{R}^{2}\right)$ was calculated after demonstration of the linearity between concentration at $\mathrm{X}$-axis and peak areas on $\mathrm{Y}$-axis. Each of the concentration samples was run in triplicate (10-13).

\section{Specificity}

In order to determine specificity, a reference standard was injected which was followed by an injection of the sample solution. The chromatographs of standard as well as sample solution were compared and obtained chromatographs were used for detecting any interfering peaks which may result from the presence of any degradation product. Six replicates of each reference solution and sample solution were examined chromatographically for the specificity of the developed analytical method (13).

\section{Accuracy}

It is the closeness of agreement between the value found experimentally and the concentration value accepted either as a conventional true value or an accepted reference value (12). The known con-

Table 2. Levels of independent factors used in Box-Behnken design for optimization.

\begin{tabular}{|l|c|c|c|}
\hline \multirow{2}{*}{ Factors } & \multicolumn{3}{|c|}{ Factors level } \\
\cline { 2 - 4 } & -1 & 0 & +1 \\
\hline $\mathrm{X}_{1}: \lambda_{\max }(\mathrm{nm})$ & 205 & 212 & 220 \\
\hline $\mathrm{X}_{2}:$ flow rate $(\mathrm{mL} / \mathrm{min})$ & 0.5 & 1.25 & 2 \\
\hline $\mathrm{X}_{3}: \mathrm{pH}$ & 3 & 3.5 & 4 \\
\hline
\end{tabular}


centrations of standard drugs corresponding to 15 , 30,45 and $60 \mathrm{ng} / \mathrm{mL}$ from 3 separate pre-analyzed samples of lipospheres containing SG and EP were spiked into using the standard method. To determine the accuracy of the method, each concentration level was subjected thrice to recover drugs using the HPLC system (13).

\section{Precision}

Precision is the closeness of agreement between a series of measurements obtained from multiple sampling of the same homogeneous sample under the prescribed conditions. It can be considered at three levels: repeatability, intermediate precision and reproducibility (12). Both intraday and interday studies were carried out to establish the precision of the newly developed HPLC method and the \% RSD was calculated. In intra-day precision, it was done by injecting 3 sample solutions at various concentration levels $(05,10$ and $20 \mathrm{ng} / \mathrm{mL})$ into the system at 3 appropriate time intervals within a day (beginning, middle, end of a day). For intraday precision studies, the value of $\%$ RSD should be less than $5.96 \%$. In the case of inter-day precision studies, injections of similar concentrations of sample solu- tion as that for intraday studies were made into the HPLC system on 3 different consecutive days (thrice a day) in order to determine \% RSD. The value of $\%$ RSD for inter-day precision should be less than $7.70 \%$ (14).

\section{Limits of quantification (LOQ) and limits of detection (LOD)}

To determine the minimum detectable amount (lowest concentration yielding peak height 3 times greater than that of baseline noise), limits of detection (LOD) studies were performed while LOQ was aimed at measuring the minimum quantifiable amount (the lowest concentration yielding peak height that is 10 times the signal to noise ratio) of drugs (15). LOD and LOQ were calculated as;

$$
\begin{aligned}
& \mathrm{LOD}=3 \mathrm{Q} / \mathrm{S} \\
& \mathrm{LOQ}=10 \mathrm{Q} / \mathrm{S}
\end{aligned}
$$

\section{Assay of lipospheres}

For a quantitative analysis of the prepared lipospheres, a specific amount (2 g) of lipospheres was crushed and dissolved in $100 \mathrm{~mL}$ of mobile phase and $10 \mathrm{ng} / \mathrm{ml}$ of each drug concentration was obtained by suitable dilutions. The obtained solu-
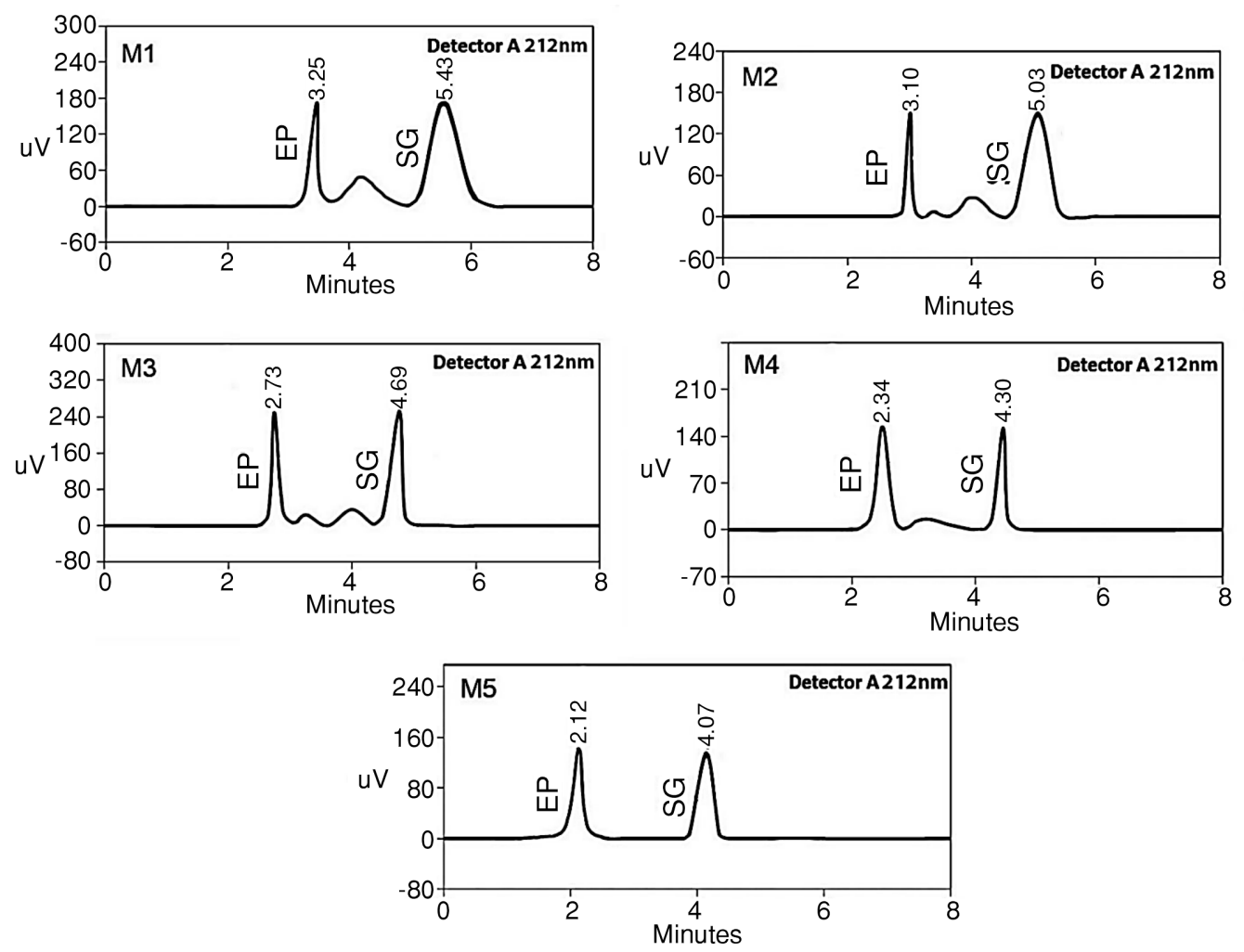

Figure 1. HPLC chromatograms indicating EP and SG Peaks with five different mobile phases. 
Table 3. Actual levels of independent (X1-X3) and dependent factors $\left(\mathrm{Y}_{1}-\mathrm{Y}_{4}\right)$.

\begin{tabular}{|c|c|c|c|c|c|c|c|}
\hline $\begin{array}{c}\text { Run } \\
\text { No }\end{array}$ & $\begin{array}{c}\lambda \max (\mathrm{nm}) \\
\left(\mathrm{X}_{1}\right)\end{array}$ & $\begin{array}{c}\text { FlowRate } \\
\left(\mathrm{X}_{2}\right)\end{array}$ & $\begin{array}{l}\mathrm{pH} \\
\left(\mathrm{X}_{3}\right) \\
\end{array}$ & $\mathrm{RT}-1\left(\mathrm{Y}_{1}\right)$ & $\mathrm{RT}-2\left(\mathrm{Y}_{2}\right)$ & $\mathrm{TF}-1\left(\mathrm{Y}_{3}\right)$ & $\mathrm{TF}-2\left(\mathrm{Y}_{4}\right)$ \\
\hline 1 & 205 & 0.5 & 3.5 & 5.3 & 6.7 & 1.6 & 1.9 \\
\hline 2 & 220 & 0.5 & 3.5 & 5.1 & 6.3 & 1.3 & 1.6 \\
\hline 3 & 212 & 1.25 & 3.5 & 2.3 & 4.4 & 1.1 & 1.4 \\
\hline 4 & 205 & 2 & 3.5 & 4.4 & 4.7 & 1.5 & 1.8 \\
\hline 5 & 212 & 1.25 & 3.5 & 2.3 & 4.4 & 1.1 & 1.4 \\
\hline 6 & 212 & 2 & 4.0 & 2.8 & 4.9 & 1.6 & 1.8 \\
\hline 7 & 212 & 1.25 & 3.5 & 2.3 & 4.4 & 1.1 & 1.4 \\
\hline 8 & 220 & 1.25 & 3.0 & 2.2 & 5.0 & 0.97 & 1.1 \\
\hline 9 & 212 & 2 & 3.0 & 2.0 & 4.0 & 1.0 & 1.3 \\
\hline 10 & 220 & 2 & 3.5 & 3.6 & 5.5 & 1.2 & 1.5 \\
\hline 11 & 220 & 1.25 & 4.0 & 3.8 & 5.8 & 1.4 & 1.7 \\
\hline 12 & 212 & 1.25 & 3.5 & 2.3 & 4.4 & 1.1 & 1.4 \\
\hline 13 & 205 & 1.25 & 4.0 & 5.0 & 6.2 & 1.5 & 1.8 \\
\hline 14 & 205 & 1.25 & 3.0 & 4.4 & 5.3 & 1.3 & 1.8 \\
\hline 15 & 212 & 0.5 & 3.0 & 2.2 & 4.1 & 1.2 & 1.3 \\
\hline 16 & 212 & 1.25 & 3.5 & 2.3 & 4.4 & 1.1 & 1.4 \\
\hline 17 & 212 & 0.5 & 4.0 & 5.1 & 5.3 & 1.4 & 1.7 \\
\hline
\end{tabular}

$\mathrm{X}_{1}=\lambda_{\text {max }}, \mathrm{X}_{2}=$ flowrate, $\mathrm{X}_{3}=\mathrm{pH}, \mathrm{Y}_{1}=\mathrm{RT}(\mathrm{EP}), \mathrm{Y}_{2}=\mathrm{RT}(\mathrm{SG}), \mathrm{Y}_{3}=\mathrm{TF}(\mathrm{EP}), \mathrm{Y}_{4}=\mathrm{TF}(\mathrm{SG})$.

Table 4. Statistical outcomes of regression analysis of tailing factors and retention times for Enalapril and Saxagliptin.

\begin{tabular}{|c|c|c|c|c|}
\hline Parameters & $\begin{array}{c}\text { EP retention } \\
\text { time }\left(\mathrm{Y}_{1}\right)\end{array}$ & $\begin{array}{c}\text { SG retention } \\
\text { time }\left(\mathrm{Y}_{2}\right)\end{array}$ & $\begin{array}{c}\text { EP-tailing } \\
\text { factor }\left(\mathrm{Y}_{3}\right)\end{array}$ & $\begin{array}{c}\text { SG-tailing } \\
\text { factor }\left(\mathrm{Y}_{4}\right)\end{array}$ \\
\hline $\mathrm{R}^{2}$ & 0.9511 & 0.9819 & 0.9641 & 0.9906 \\
Adj.R ${ }^{2}$ & 0.8883 & 0.9586 & 0.93311 & 0.9785 \\
Pred.R ${ }^{2}$ & 0.6183 & 0.7565 & 0.7923 & 26.866 \\
Adequate precision & 11.328 & 19.539 & 0.26 & 0.033 \\
Standard deviation & 0.41 & 0.042 & 5.09 & 1.56 \\
Mean & 3.48 & 1.26 & 5.16 & 2.10 \\
C.V. $\%)$ & 11.80 & 3.31 & 0.20 & 0.12 \\
PRESS & 18.92 & & & 2.72 \\
\hline
\end{tabular}

tions were then filtered and injected for quantitative assay.

\section{Freeze-thaw stability}

For testing the stability of drugs in the mobile phase, the solutions of drugs in mobile phase 6 $\mathrm{ng} / \mathrm{mL}$ were further analyzed at different conditions of temperature. The solutions were stored in a wellclosed container for $12 \mathrm{~h}$ at -15 to $-20^{\circ} \mathrm{C}$ and at ambient temperature. Finally, the stored samples were analyzed to determine \% RSD (15).

\section{System suitability}

These tests are based on the concept that the equipment, sample and analytical operations are an integral part of the system and can be evaluated like that. The system suitability studies for the developed HPLC method were performed by shifting the experiments from the Shimadzu HPLC system to the Agilent system by different operators in similar chromatographic conditions. Six injections of standard solutions were analyzed with the Agilent HPLC system to demonstrate the suitability of the 
system. The acceptance criterion was determined in terms of tailing factor, a number of theoretical plates with \% RSD value (12-13).

\section{RESULTS AND DISCUSSION}

The new HPLC technique for the instantaneous determination of SG and EP in the mobile phase was validated. For this purpose, the conditions of chromatography were first optimized to the maximum extent and then validated. For screening of the mobile phase, during the preliminary studies, five mobile phases were tested. According to the results of these studies, a mixture of acetonitrile : methanol and phosphate buffer of $\mathrm{pH}-3$ (M5) in ratio of $40: 40: 20$ have shown the most optimized results because of enhanced solubility and stability of the analytes i.e. SG and EP. Figure 1 showed the respective chromatograms for these mobile phases and maximum separation of analytes and a maximum resolution of peaks were achieved with M5.

\section{Data optimization of retention time and tailing factor by Box-Behnken design}

Optimization studies were performed to deliberately alter conditions like $\mathrm{pH}$ of mobile phase, mobile phase flow rate and wavelength $\left(\lambda_{\max }\right)$ to study their effect on tailing factors and retention times of both drugs. For purpose of highlighting the effect of detecting wavelength $\left(\mathrm{X}_{1}\right)$, mobile phase flow rate $\left(\mathrm{X}_{2}\right)$ and $\mathrm{pH}\left(\mathrm{X}_{3}\right)$ of mobile phase on retention times of EP $\left(\mathrm{Y}_{1}\right), \mathrm{SG}\left(\mathrm{Y}_{2}\right)$, and tailing factors of $\mathrm{EP}\left(\mathrm{Y}_{3}\right)$ and SG $\left(\mathrm{Y}_{4}\right)$ by using BBD, selected optimized mobile phase (M5) was used in suggested 17 runs (Table 3) and polynomial equations were generated to discuss the impact of interactions of these studied variables. According to equations 3 to 6 , the quadratic impact of studied variables on tailing factors and retention times of both drugs was quite prominent as the data of responses followed the quadratic model. The ratio of maximum to minimum values for tailing factors and retention times existed at less than three, suggesting the adequacy of applied models and prohibiting further model transformation. As shown in Table 4, the results for each response have indicated the quadratic model significance. Similarly, respective adjusted $\mathrm{R}^{2}$ values were found to be in close contact with predicted values of the regression coefficient $\left(\mathrm{R}^{2}\right)$. The signal to noise ratio was measured with adequate precision. Its value of greater than 4 for tailing factors and retention times of EP and SG showing the suitability and adequacy of the model. The followed quadratic model was also analyzed for lack of fit (LOF) which was not considered as significant.
The response retention time $\left(\mathrm{Y}_{1}\right)$ and tailing factor $\left(\mathrm{Y}_{3}\right)$ of EP followed the quadratic model and their obtained polynomial equations were as followed:

Tailing Factor $(\mathrm{EP})=136.91-3.54 \mathrm{X}_{1}-3.98 \mathrm{X}_{2}$ $-8.72 \mathrm{X}_{3}+5.42 \mathrm{X}_{1} \mathrm{X}_{2}+3.23 \mathrm{X}_{1} \mathrm{X}_{3}+4.85 \mathrm{X}_{2} \mathrm{X}_{3}$

$+4.76 X_{1}^{2}+2.36 X_{2}^{2}+2.982 .36 X_{3}^{2}$

Retention Time $(\mathrm{EP})=11.44 .30-10.67(4) \mathrm{X}_{1}$ $-1.43 X_{2}-18.71 X_{3}-0.054 X_{1} X_{2-}+0.66 X_{1} X_{3}$ $-0.2 \mathrm{X}_{2} \mathrm{X}_{3}+0.34 \mathrm{X}_{1}^{2}+1.96 \mathrm{X}_{2}^{2}+0.85 \mathrm{X}_{3}^{2}$

The flow rate $\left(\mathrm{X}_{2}\right)$ of the mobile phase significantly affects the tailing factor $\left(\mathrm{Y}_{3}\right)$ and retention time $\left(\mathrm{Y}_{1}\right)$ of EP suggesting that by decreasing the flow rate, the tailing factor and retention time of EP could also be decreased. In the current study, it seems that wavelength $\left(\mathrm{X}_{1}\right)$ and $\mathrm{pH}$ of mobile phase $\left(\mathrm{X}_{3}\right)$ has also a significant impact on the tailing factor and retention time of EP as shown in run no 15 , where retention time of $2.2 \mathrm{~min}$ with a tailing factor of 1.2 was achieved at a wavelength of $212 \mathrm{~nm}$ by running mobile phase of $\mathrm{pH} 3$ at a flow rate of 0.5 $\mathrm{mL} / \mathrm{min}$. The impact of detection wavelength and flow rate seems to be more prominent and quadratic (Figs. 2C and 3A) as compared to the effect of mobile phase $\mathrm{pH}$ on tailing factor and retention time of EP as shown in 3D graphs (Figs. 2 and 3). From ANOVA, the flow rate could be considered as a highlighted term $(p<0.05)$ for the tailing factor and retention time of EP as shown in Table 5. Manzoor et al., 2012 have achieved a definite peak of hydrochlorothiazide with nebivolol without tailing at a short retention time by adjustment of $\mathrm{pH}$ of the mobile phase and by adopting a suitable flow rate and wavelength (16).

The responses retention time $\left(\mathrm{Y}_{2}\right)$ and tailing factor $\left(\mathrm{Y}_{4}\right)$ of $\mathrm{SG}$ had observed the quadratic model and their respective equations were as followed;

Tailing Factor $(\mathrm{SG})=168.92-2.39 \mathrm{X}_{1}-2.81 \mathrm{X}_{2}$ $-11.73 \mathrm{X}_{3}+3.42 \mathrm{X}_{1} \mathrm{X}_{2}+1.25 \mathrm{X}_{1} \mathrm{X}_{3}+2.84 \mathrm{X}_{2} \mathrm{X}_{3}$ $+3.78 X_{1}^{2}+1.98 X_{2}^{2}+0.98 X_{3}^{2}$

Retention Time $(\mathrm{SG})=910.91-9.59 \mathrm{X}_{1}-15.82 \mathrm{X}_{2}$ $-2.73 \mathrm{X}_{3}+0.85 \mathrm{X}_{1} \mathrm{X}_{2}-6.85 \mathrm{X}_{1} \mathrm{X}_{3}+0.82 \mathrm{X}_{2} \mathrm{X}_{3}$ $+5.76 X_{1}^{2}+8.37 X_{2}^{2}+6.8 X_{3}^{2}$

For $\mathrm{SG}$, retention time has shown their strong dependence on all of the three studied variables. The higher wavelength within the specified range has raised the retention time of SG as indicated with runs no 10 and 11 (Table 3) whereas a retention time of 5.5 and 5.8 minutes for SG was achieved at a wavelength of $212 \mathrm{~nm}$. It was observed that $X_{1}$, $\mathrm{X}_{2}, \mathrm{X}_{1}^{2}, \mathrm{X}_{2}^{2}$ were observed as significant terms for the response tailing factor of $\mathrm{SG}\left(\mathrm{Y}_{4}\right)$. A very high- 
A

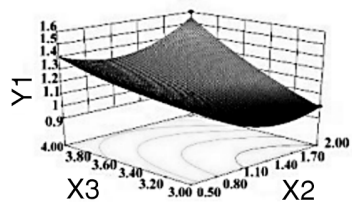

D

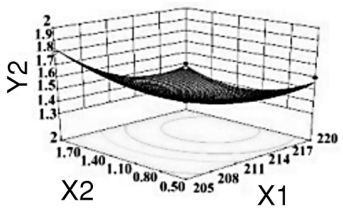

B

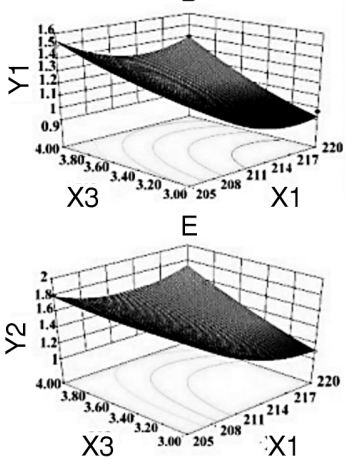

C

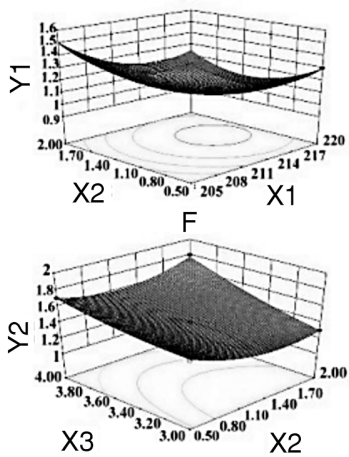

Figure 2. 3D Surface graphs indicating the impact of $\lambda \max (\mathrm{X} 1)$, mobile phase flow rate $(\mathrm{X} 2)$ and $\mathrm{pH}$ of mobile phase (X3) on Retention Times (Y1 and Y2) of EP and SG.

A

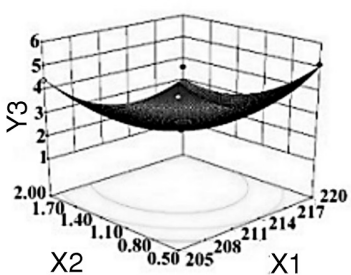

D

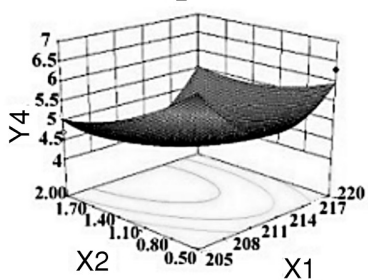

B

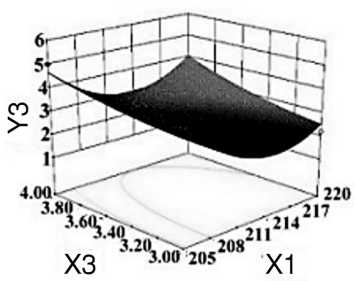

E

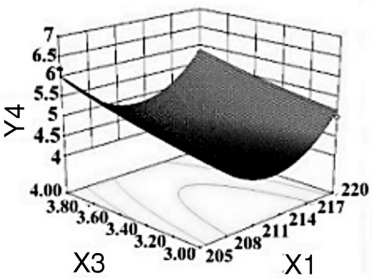

C

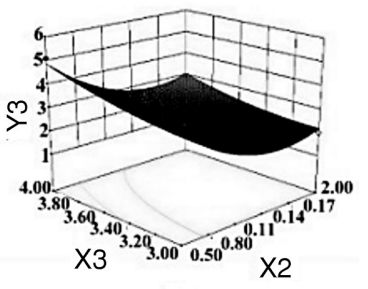

F

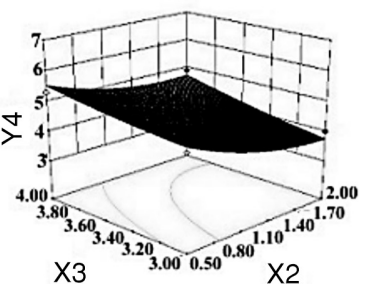

Figure 3. 3D Surface graphs indicating the impact of $\lambda \max (\mathrm{X} 1)$, mobile phase flow rate (X2) and pH of mobile phase (X3) on and tailing factors (Y3 and Y4) of EP and SG.

Table 5. ANOVA test showing the effect of studied factors on retention times and tailing factors with their corresponding p-values.

\begin{tabular}{|l|c|c|c|c|c|c|c|c|}
\hline \multirow{2}{*}{ Variables } & \multicolumn{2}{|c|}{$\begin{array}{c}\text { EP retention time } \\
\left(\mathrm{Y}_{1}\right)\end{array}$} & \multicolumn{2}{c|}{$\begin{array}{c}\text { SG retention time } \\
\left(\mathrm{Y}_{2}\right)\end{array}$} & \multicolumn{2}{c|}{$\begin{array}{c}\text { EP-tailing factor } \\
\left(\mathrm{Y}_{3}\right)\end{array}$} & \multicolumn{2}{c|}{$\begin{array}{c}\text { SG-tailing factor } \\
\left(\mathrm{Y}_{4}\right)\end{array}$} \\
\cline { 2 - 10 } & F-Value & p-value & F-Value & p-value & F-Value & p-value & F-Value & p-value \\
\hline Model & 35.64 & $<0.0001$ & 34.75 & $<0.0001$ & 47.71 & $<0.0001$ & 82.31 & $<0.000$ \\
\hline $\mathrm{X}_{1}$ - $\lambda_{\max }$ & 18.39 & 0.0043 & 3.54 & 0.5813 & 8.41 & 0.1629 & 228.42 & $<0.000$ \\
\hline $\mathrm{X}_{2}$-flow rate & 35.22 & $<0.0001$ & 31.87 & $<0.0001$ & 43.65 & $<0.0001$ & 10.50 & 0.0143 \\
\hline $\mathrm{X}_{3}$ - pH & 19.44 & $<0.0001$ & 19.54 & $<0.0001$ & 146.18 & $<0.0001$ & 197.52 & $<0.000$ \\
\hline $\mathrm{X}_{1} \mathrm{X}_{2}$ & 0.65 & 0.4854 & 5.22 & 0.0529 & 1.21 & 0.7132 & 1.34 & 0.8907 \\
\hline $\mathrm{X}_{1} \mathrm{X}_{3}$ & 1.87 & 0.2787 & 3.632 & 0.0854 & 8.58 & 0.0485 & 84.00 & $<0.000$ \\
\hline $\mathrm{X}_{2} \mathrm{X}_{3}$ & 0.57 & 0.7233 & 1.28 & 0.8071 & 24.96 & $<0.0001$ & 21.00 & 0.0023 \\
\hline $\mathrm{X}_{1}{ }^{2}$ & 44.76 & $<0.0001$ & 75.43 & $<0.0001$ & 51.57 & $<0.0001$ & 103.77 & $<0.000$ \\
\hline $\mathrm{X}_{2}{ }^{2}$ & 27.49 & $<0.0001$ & 8.98 & 0.0475 & 56.99 & $<0.0001$ & 74.30 & $<0.000$ \\
\hline $\mathrm{X}_{3}{ }^{2}$ & 1.54 & 0.3221 & 1.31 & 0.7467 & 7.16 & 0.0503 & 5.53 & 0.0514 \\
\hline
\end{tabular}


er value of $\mathrm{pH}$ of the mobile phase and flow rate ( $2 \mathrm{~mL} / \mathrm{min}$ ) would have a positive effect on the retention time of $\mathrm{SG}$ because they have a positive sign in equation 6 . For the tailing factor of $\mathrm{SG}\left(\mathrm{Y}_{4}\right)$, the effect of $\mathrm{pH}$ of mobile phase seems to be more prominent as compared to the effect of wavelength and flow rate (equation 5) but very higher values of $\mathrm{pH}$ of mobile phase and flow rate would have a negligible effect on tailing factor for SG. In 3D graphs (Figs. 2 and 3), the interaction of $X_{1} X_{2}$ and $X_{3} X_{1}$ was found to be more prominent and quadratic as compared to the interaction of $\mathrm{X}_{2} \mathrm{X}_{3}$. Prasad et al., 2015 have observed a retention time of $6.92 \mathrm{~min}$ for SG in their study (4) and the current study showed a minimum retention time of 4.00 mins (Run no 9 and 15). However, the suitability of performed assay for method development was indicated by the tailing factor for EP that ranged from 0.97 to 1.6 and 1.1 to 1.9 for SG.

In addition to optimization studies that were performed to obtain well-separated sharp peaks of the drugs, the method was further validated under different chromatographic conditions and at suitable retention time.

\section{Validation of the method \\ Linearity}

As deduced from the chromatograms of EP and SG shown in Figure 4, the relationship between peak area and analyte concentration was linear. The linearity was found to be within acceptable limits proving the suitability of the developed method as recommended by ICH guidelines which describe as the linearity should be established on at least five concen-
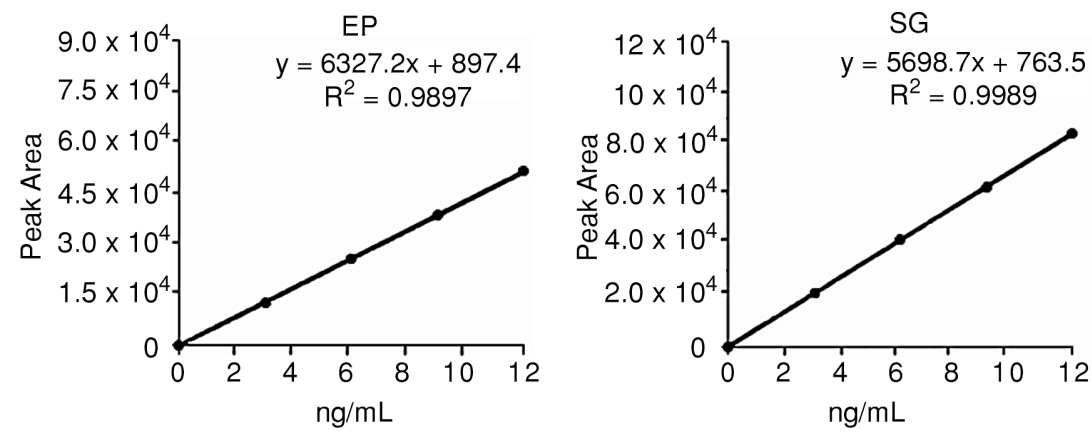

Figure 4. Linearity profiles of EP and SG at the concentration range of $02-12 \mathrm{ng} / \mathrm{mL}$.

Table 6. Mean values of recovery of EP and SG from prepared samples $(n=3)$.

\begin{tabular}{|c|c|c|c|c|c|c|}
\hline \multirow{2}{*}{$\begin{array}{l}\text { Sample } \\
\text { number }\end{array}$} & \multicolumn{3}{|c|}{ EP } & \multicolumn{3}{|c|}{$\mathrm{SG}$} \\
\hline & $\begin{array}{l}\text { Conc. Added } \\
(\mathrm{ng} / \mathrm{mL})\end{array}$ & $\begin{array}{l}\text { Recovered } \\
\text { conc. }(\%)\end{array}$ & $\begin{array}{c}\text { RSD } \\
(\%)\end{array}$ & $\begin{array}{c}\text { Conc. Added } \\
(\mathrm{ng} / \mathrm{mL})\end{array}$ & $\begin{array}{c}\text { Recovered } \\
\text { Conc. }(\%)(\%)\end{array}$ & RSD \\
\hline 1 & 15.00 & 99.89 & \pm 0.28 & 15.00 & 99.44 & \pm 0.27 \\
\hline 2 & 30.00 & 98.88 & \pm 0.42 & 30.00 & 98.83 & \pm 0.31 \\
\hline 3 & 45.00 & 99.61 & \pm 0.37 & 45.00 & 99.18 & \pm 0.35 \\
\hline 4 & 60.00 & 99.52 & \pm 0.19 & 60.00 & 98.88 & \pm 0.22 \\
\hline
\end{tabular}

Table 7. Intra-day precision for HPLC method validation of EP and SG $(n=6)$.

\begin{tabular}{|c|c|c|c|c|c|c|}
\hline \multirow{2}{*}{$\begin{array}{c}\text { Conc. } \\
(\mathrm{ng} / \mathrm{mL})\end{array}$} & $\begin{array}{c}\text { Recovered Conc. } \\
(\text { mean } \pm \text { SD })\end{array}$ & $\begin{array}{c}\text { Accuracy } \\
(\%)\end{array}$ & $\begin{array}{c}\text { RSD } \\
(\%)\end{array}$ & $\begin{array}{c}\text { Recovered Conc. } \\
(\text { mean } \pm \text { SD })\end{array}$ & $\begin{array}{c}\text { Accuracy } \\
(\%)\end{array}$ & $\begin{array}{c}\text { RSD } \\
(\%)\end{array}$ \\
\hline 05 & $4.87 \pm 1.576$ & 97.4 & 1.52 & $4.84 \pm 1.38$ & 96.8 & 1.19 \\
\hline 10 & $9.71 \pm 0.946$ & 97.1 & 1.37 & $9.61 \pm 1.19$ & 96.6 & 1.26 \\
\hline 20 & $19.55 \pm 2.182$ & 97.8 & 1.72 & $19.24 \pm 2.6$ & 96.2 & 1.44 \\
\hline
\end{tabular}


Table 8. Inter-day precision for HPLC method validation of EP and SG with \% accuracy.

\begin{tabular}{|c|c|c|c|c|c|c|}
\hline \multirow{2}{*}{ Days } & \multicolumn{3}{|c|}{ EP (\% Recovery) } & \multicolumn{3}{c|}{ SG (\% Recovery) } \\
\cline { 2 - 7 } & $\begin{array}{c}\text { Trial-1 } \\
05 \mathrm{ng} / \mathrm{mL}\end{array}$ & $\begin{array}{c}\text { Trial-2 } \\
10 \mathrm{ng} / \mathrm{mL}\end{array}$ & $\begin{array}{c}\text { Trial-3 } \\
20 \mathrm{ng} / \mathrm{mL}\end{array}$ & $\begin{array}{c}\text { Trial-1 } \\
05 \mathrm{ng} / \mathrm{mL}\end{array}$ & $\begin{array}{c}\text { Trial-2 } \\
10 \mathrm{ng} / \mathrm{mL}\end{array}$ & $\begin{array}{c}\text { Trial-3 } \\
20 \mathrm{ng} / \mathrm{mL}\end{array}$ \\
\hline Day 1 & 99.71 & 99.17 & 98.83 & 99.03 & 97.94 & 98.64 \\
\hline Day 2 & 99.07 & 97.99 & 99.11 & 98.91 & 99.09 & 97.92 \\
\hline Day 3 & 99.09 & 99.0 & 97.87 & 98.79 & 98.41 & 97.58 \\
\hline \% RSD & 1.08 & 1.17 & 1.26 & 1.48 & 1.62 & 1.73 \\
\hline
\end{tabular}

Table 9. Results of stability-indicating parameters of standard solutions of both drugs in mobile phase.

\begin{tabular}{|c|c|c|c|c|c|c|}
\hline Parameters & \multicolumn{3}{|c|}{ EP } & \multicolumn{3}{c|}{ SG } \\
\hline TIME & $0(\mathrm{~h})$ & $24(\mathrm{~h})$ & $48(\mathrm{~h})$ & $0(\mathrm{~h})$ & $24(\mathrm{~h})$ & $48(\mathrm{~h})$ \\
\hline Recovery (\%) & 98.92 & 99.06 & 97.87 & 99.57 & 98.92 & 98.09 \\
\hline R.T (\% RSD) & 0.22 & 0.18 & 026 & 0.16 & 0.37 & 0.42 \\
\hline P.A (\% RSD) & 0.17 & 0.41 & 0.31 & 0.23 & 0.28 & 0.39 \\
\hline P.H (\% RSD) & 0.21 & 0.36 & 0.43 & 0.33 & 0.44 & 0.49 \\
\hline
\end{tabular}

R.T: Retention time. P.A: Peak area, P.H: Peak height.

tration levels in a specific range with the determination of percentage relative standard deviation $(\%$ RSD). The specific concentration range (02 to 12 $\mathrm{ng} / \mathrm{mL}$ ) was observed to follow the confirmed linearity pattern. The regression equations for the linearity of EP and for SG were obtained by plotting drug concentration (x) versus peak area (y) as shown in Figure 4 . The value of the correlation coefficient $\left(R^{2}\right)$ calculated by the least square method was greater than $0.998\left(R^{2}=0.9989\right.$ for $\mathrm{SG}$ and $\mathrm{R}^{2}=0.9995$ for $\left.\mathrm{EP}\right)$ that confirmed the data fitting for the linearity pattern and \% RSD was found to be less than $0.5 \%$ at each run of the experiment for linearity establishment. Zhang et al., 2015 had reported the linearity at a concentration level of 2 to $12 \mu \mathrm{g} / \mathrm{mL}$ in order to estimate alogliptin in pharmaceutical formulations (17).

\section{Specificity}

The sample solution of EP-SG and standard solution separately injected in the HPLC system have not shown any interfering peak verifying the specificity of the method. As observed from the chromatograms, the peaks of SG and EP were well separated and free from any interfering peaks. The retention times of $4.07 \mathrm{~min}$ and 2.12 min were observed for SG and EP respectively. Figure 5A indicating the chromatogram obtained for EP-SG standard solution while Figure 5B indicating the chromatogram obtained for EP-SG sample solution showing the precision of the developed procedure.

\section{Accuracy}

The mean recoveries expressed in terms of $\%$ RSD for SG and EP were indicated in Table 6. ICH guidelines instruct that at least nine observations for a specific concentration range of analyte or three concentrations of an analyte with three replicate of each concentration level should be used. This study consisted of three replicates of four different concentration levels of each drug. In recovery studies for accuracy at the concentration range of 15 to 60 $\mathrm{ng} / \mathrm{mL}$, results have shown a great accuracy of the method as illustrated by mean recovery values of EP (99.89\%) and SG (99.44\%). The \% RSD value for the study was also found to be less than $2 \%$. Similar results for the recovery studies (99-101\%) have been reported for nebivolol hydrochloride by Shah et al., 2008 with \% RSD value of less than 2\% (18).

\section{Precision}

For intra-day precision or repeatability, a minimum of nine measurements over the specific concentration range under similar experimental conditions for short time intervals were carefully considered for the results as per ICH recommendations. The precision of the current study was evaluated by evaluating the EP-SG containing samples at three concentration levels at different time intervals within the same day under the same chromatographic conditions and results were presented in Table 7 and spectra for the precision study was shown in Figure 5B. The \% RSD value with \% accuracy of data for 
the determined concentrations of SG and EP was observed to be less than $2 \%$ (Table 7) suggesting the precision and accuracy of the developed method. From the results of EP-SG samples spiked at three consecutive days, inter-day precision was calculated and $\%$ RSD of less than $2 \%$ at a concentration range of 05-20 ng/mL (Table 8). Seerapu and Srinivasan had also reported intraday and inter-day precisions in the form of $\%$ RSD values of 0.86 and 0.53 for the HPLC method development of EP (19).

\section{LOD and LOQ}

The limit of detection for EP and SG was found to be $0.006 \mu \mathrm{g} / \mathrm{mL}$ and $0.012 \mu \mathrm{g} / \mathrm{mL}$ respectively from the currently developed method. However, the LOQ was observed as $0.22 \mu \mathrm{g} / \mathrm{mL}$ for the EP and 0.25 $\mu \mathrm{g} / \mathrm{mL}$ for SG respectively which verifies the sensitivity of the method. For the developed method, \% RSD value suggested the acceptability, sensitivity and suitability which was found to be less than $2 \%(n=6)$ for both LOD and LOQ. Similar findings were reported by Manzoor et al., 2012 with LOD and LOQ (0.0309 $\mu \mathrm{g} / \mathrm{mL}$ and $0.0046 \mu \mathrm{g} / \mathrm{mL}$ ) in the simultaneous determination of nebivolol and hydrochlorothiazide (16).

\section{Freeze-thaw stability}

A comparison of \% RSD values of peak area and peak height of sample solutions in the mobile phase at a concentration level of $6 \mathrm{ng} / \mathrm{mL}$ overtime was made to measure the stability of SG and EP in the mobile phase. The occurrence of any significant degradation during freeze-thaw cycles $\left(-20^{\circ} \mathrm{C}\right.$ to room temperature) was not observed. The standard solutions of both drugs in the mobile phase remained stable up to $48 \mathrm{~h}$ under normal storage conditions as confirmed from the findings of stability studies (Table 9). The stability of standard solutions of both drugs in the mobile phase was considered acceptable since the change in sample solutions assessed at various time intervals was observed $<2 \%$ for freshly prepared sample solution, after 24 and $48 \mathrm{~h}$. Both drugs were found to be stable with no significant change $(<1 \%$ changes in area) signifying that prepared sample solutions of SG and EP can be assayed within 48 h of preparations. Shah et al., 2008 have considered the \% RSD level of $2 \%$ in the solution stability studies for the HPLC method development of nebivolol in pharmaceutical formulations (18).

\section{Assay of lipospheres}

In the assay of the lipospheres by freshly developed and validated methods, lipospheres have demonstrated $98.91 \%$ contents of EP and $99.89 \%$ of SG. Figure 6 indicated the chromatograms obtained from standard solutions of drugs and from prepared lipospheres sample solutions.
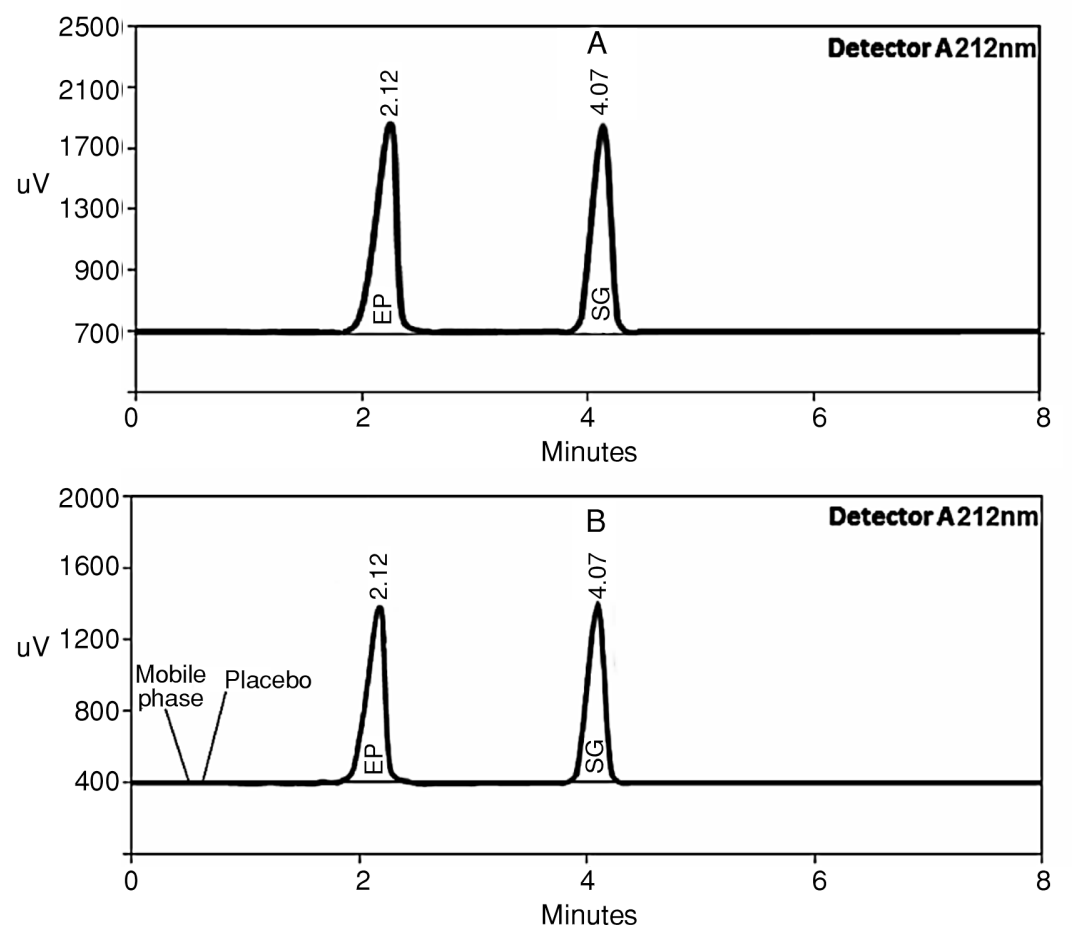

Figure 5. HPLC Chromatograms of EP and SG indicating specificity (A) and precision (B) of developed procedure. 

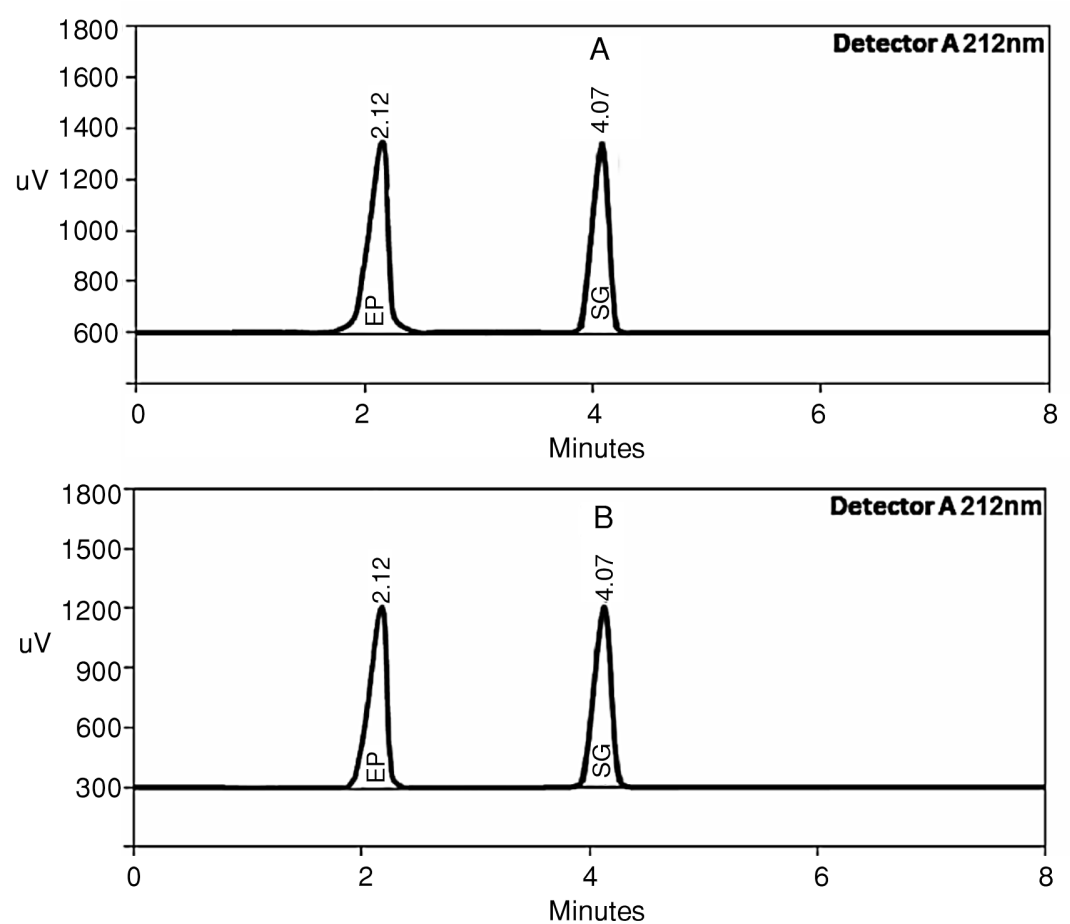

Figure 6. HPLC spectra of EP and SG containing standard solution (A) and HPLC spectra of EP and SG from prepared SLMs sample solutions.

Table 10. Results of system suitability studies for EP and SG.

\begin{tabular}{|c|c|c|}
\hline Parameters & EP & SG \\
\hline Tailing Factor & 1.15 & 1.1 .1 \\
\hline No of Theoretical plates & 9473 & 8895 \\
\hline Retention Time (min) & 2.13 & 4.03 \\
\hline \% RSD & 0.3 & 0.43 \\
\hline
\end{tabular}

\section{System suitability}

Validation of a newly developed method was done by system suitability studies and six replicates of $5 \mathrm{ng} / \mathrm{mL}$ of standard solution were injected in the Agilent HPLC system. This study expressed the system suitability in the form of $\%$ RSD, theoretical plate number, tailing factor, and retention time for both drugs as shown in Table 10. These studied parameters for the system suitability were found to be within limits with \% RSD as less than $1 \%$ for both drugs indicating that change in system and operator had brought no significant change in outcomes of the developed method.

\section{CONCLUSION}

Our literature review accomplishes that this is the first description for the development and validation of an HPLC method for the simultaneous estimation of SG and EP in a formulation. The method was applied successfully for the quantification of mentioned drugs in lipospheres. The method was optimized using Box-Behnken Design in which the effect of flowrate, wavelength and $\mathrm{pH}$ of the buffer was observed on tailing factor and retention time of drugs. During validation as per ICH Guidelines, the designed analytical method proved itself to be sensitive, accurate, robust, precise, easy, and economical due to high percentage yield and \% RSD values within limits. Convincingly, the method can be used for the rapid detection of EP-SG individually as well as in a combination. It can also be used for the routine procedures of quality control. In the future, analysis of stability can be established for the same combination of drugs in a suitable solvent and numerous biological fluids. 


\section{Conflict of interest}

The authors declare no conflict of interest.

\section{REFERENCES}

1. American Diabetes Association: Diabetes Care 36, S67 (2013).

2. American Diabetes Association: Diabetes Care 25, 71 (2002).

3. Sowers J.R., Lastra G., Rocha R., Seifu Y., Crikelair N., Levy D.G.: J. Clin. Hypertens. (Greenwich). 10, 668 (2008).

4. Prasad P.B.N., Satyanaryana K., Krishnamohan G.: Am. J. Anal. Chem. 6, 841 (2015).

5. Thongnopnua P., Poeaknapo C.: J. Pharm. Biomed. Anal. 37, 763 (2005).

6. Santos E.L., Souza K.D.P., Silva E.D.D., Batista E.C., Martins P.J.F., et al.: Biochem. Pharmcol. 78, 951 (2009).

7. Pawar P.Y., Joshi R.S., Jangale K.N., Wagh S.K., Sandhan V.P.: Der Pharmacia Sinica 2, 121 (2011).

8. International Conference on Harmonization, I. Q2 (R1): Validation of analytical procedures: Text and methodology. In ICH, Geneva 2005.
9. Xiong Y., Guo D., Wang L., Zheng X., Zhang Y., Chen J.: Int. J. Pharm. 371, 197 (2009).

10. Jaspart S., Piel G., Delattre L., Evrard B.: Expert Opin. Drug Deliv. 2, 75 (2005).

11. Cheregi M., Albu F., Udrescu S., Raducanu N., Medvedovici A.: J. Chromatogr. B 124, 927 (2013).

12. Naseef H., Moqadi R., Qurt M.: J. Anal. Methods. Chem. Article ID 1902510 (2018).

13. Chittrakarn S., Janchawee B., Ruangrut P., Kansenalak S., Chethanond U., et al.: Res. Vet. Sci. 86, 503 (2009).

14. Deshpanda P.B., Butle S.R.: J. Anal. Chem. 73, 303 (2018).

15. Huang T., He Z., Yang B., Shao L., Zheng X. Duan G.: J. Pharm. Biomed. Anal. 41, 644 (2006).

16. Manzoor A., Manohara Y.N., Ravi M.C.: Int. J. Chemtech. Res. 4, 328 (2012).

17. Zhang K., Ma P., Jing W., Zhang X.: Asian J. Pharm. Sci. 10, 152 (2015).

18. Shah D., Bhatt K., Mehta R., Baldania S., Gandhi T.: Indian J. Pharm. Sci. 70, 591 (2008).

19. Seerapu S., Srinivasan B.: Indian J. Pharm. Sci. 72, 667 (2010). 